\title{
MicroRNA-138 inhibits SOX12 expression and the proliferation, invasion and migration of ovarian cancer cells
}

\author{
MIAOMIAO QU ${ }^{1 *}$, YONGNING ZHU ${ }^{1 *}$ and MENG JIN ${ }^{2}$ \\ Departments of ${ }^{1}$ Obstetrics and ${ }^{2}$ Gastrointestinal Surgery, \\ The Affiliated Hospital of Jining Medical University, Jining, Shandong 272100, P.R. China
}

Received January 10, 2017; Accepted April 13, 2018

DOI: $10.3892 /$ etm.2018.6375

\begin{abstract}
The aim of the present study was to investigate the expression and biological functions of microRNA (miR)-138 in ovarian cancer at the tissue and cellular levels, as well as its underlying mechanisms. A total of 47 patients with ovarian cancer were included in the present study. Ovarian cancer tissues were subjected to staging classification according to the FIGO 2000 criteria. Lymphatic metastasis was also examined. Ovarian cancer A2780 cells were transfected using liposomes. Reverse transcription-quantitative polymerase chain reaction was used to measure the expression of miR-138. A Cell-Counting Kit 8 assay was used to examine cell viability, while a Transwell assay was employed to study cell invasion and migration. The effects of miR-138 on SOX12 protein expression were examined by western blot analysis. A dual luciferase reporter assay was performed to identify the direct interaction between miR-138 and SOX12 gene. Expression of miR-138 was downregulated in ovarian cancer tissues. The level of miR-138 in patients with ovarian cancer with lymphatic metastasis was significantly lower compared with patients without lymphatic metastasis. However, expression of miR-138 was not associated with the stage of ovarian cancer. Upregulation of miR-138 inhibited the proliferation and suppressed the invasion and migration of A2780 cells. SOX12 promoted the proliferation, invasion and migration of A2780 cells. In addition, miR-138 downregulated the expression of SOX12 via binding with the 3'-UTR of SOX12 gene. The present study demonstrates that miR-138 expression is downregulated in ovarian cancer tissues and miR-138 acts as a tumor suppressor gene by inhibiting SOX12 expression and the proliferation, invasion and migration of ovarian cancer cells.
\end{abstract}

Correspondence to: Dr Miaomiao Qu, Department of Obstetrics, The Affiliated Hospital of Jining Medical University, 79 Guhuai Road, Jining, Shandong 272100, P.R. China

E-mail:wszzoo@126.com

*Contributed equally

Key words: microRNA-138, SOX12, ovarian cancer

\section{Introduction}

Cervical cancer, ovarian cancer and endometrial cancer are the three most common malignant tumor types of the female genital system $(1,2)$. Ovarian cancer accounts for only $4 \%$ of malignant tumors in women, but it has the highest mortality rate among all gynecological malignant tumor types $(3,4)$. Recurrence and early metastasis of tumor cells are the primary reasons for the poor prognosis of patients with ovarian cancer (5). Ovarian tissue is located deep within the female pelvic cavity and the symptoms of ovarian cancer are usually hard to detect. Due to the lack of specific early diagnosis, the majority of patients who are diagnosed with ovarian cancer are in the middle or advanced stages of the disease, or have distant metastasis, leading to poor prognosis $(6,7)$. In recent years, the combination of surgery and chemotherapy has significantly improved the 5-year survival rate of patients with ovarian cancer, but the overall prognosis is still poor $(8,9)$. It is reported that the occurrence and development of ovarian cancer is a complex process that involves multiple genes, steps and stages, and the molecular mechanism of ovarian cancer is still unclear (10). Therefore, screening key genes that are associated with the malignant biological behavior of ovarian cancer will be valuable in improving the early diagnosis and treatment of ovarian cancer.

MicroRNA (miRNA or miR) molecules are non-coding small RNA molecules consisting of 18-22 nucleotides (11). miRNAs are able to regulate mRNA translation by binding with the 3'-untranslated region (3'-UTR) of target genes (12). miRNAs are involved in nearly all pathophysiological processes and stably exist in body fluids, including peripheral blood, urine and saliva, which makes them key biomarkers and therapeutic targets (13). A previous study demonstrated that expression of miRNAs is disordered in multiple tumor tissues, and miRNAs serve oncogene and tumor-suppressor gene functions (14). For example, miR-590-5p activates the Akt/extracellular signal-regulated kinase signaling pathway by downregulating expression of reversion-inducing-cysteine-rich protein with kazal motifs, resulting in the promotion of proliferation and migration in gastric cancer cells (15). In addition, miR-138 acts as a tumor-suppressor gene by regulating the expression of different genes in multiple tumor types. For example, miR-138 inhibits the invasion and metastasis of non-small cell lung cancer (NSCLC) cells by decreasing the expression of LIMK1 
gene (16). Furthermore, miR-138 suppresses the proliferation, invasion and metastasis of hepatocellular carcinoma by downregulating SOX9 gene expression (17). In colon cancer, miR-138 regulates programmed cell death protein 1 expression and inhibits distant metastasis of tumor cells (18). It has also been reported that miR-138 inhibits the proliferation, invasion and migration of ovarian cancer cells via targeted inhibition of SOX4 and hypoxia-inducible factor-1 $\alpha$ (19). Therefore, miR-138 has a variety of downstream target genes that are involved in numerous signaling pathways and biological functions. However, the expression of miR-138 in ovarian cancer tissues and its clinical importance are not yet clear. The present study aimed to investigate the expression and biological functions of miR-138 in ovarian cancer.

\section{Materials and methods}

Patients. A total of 47 female patients (age range, 32-63 years; mean age, 41.5 years) with ovarian cancer who received surgical resection at Department of Obstetrics, The Affiliated Hospital of Jining Medical University (Jining, China) between February 2014 and October 2015 were included in the present study. Patients with any other tumors, chronic basic diseases, autoimmune diseases or a history of long-term medicine use were excluded. Resected primary ovarian cancer tissues were diagnosed and classified by two individual pathologists as epithelial ovarian cancer. Contralateral normal ovarian tissues were also resected as controls. According to the FIGO 2000 criteria (20), ovarian cancer tissues were subjected to staging classification. Among all cases, 11 were at stage I, 13 were at stage II, 13 were at stage III and 10 were at stage IV. In addition, 25 cases had lymphatic metastasis, while the other 22 cases had no lymphatic metastasis. All tissues were frozen in liquid nitrogen and stored at $-80^{\circ} \mathrm{C}$. None of the patients had history of other tumors or complications, or received chemoradiotherapy or any other anti-tumor therapies. The clinical information and pathological data of all subjects were collected. All procedures were approved by the Ethics Committee of Jining Medical University. Written informed consent was obtained from all patients or their families.

Cells. Ovarian cancer A2780 cells (Type Culture Collection of the Chinese Academy of Sciences, Shanghai, China) were cultured in RPMI-1640 medium supplemented with $10 \%$ fetal bovine serum (both Thermo Fisher Scientific, Inc., Waltham, $\mathrm{MA}, \mathrm{USA})$ at $37^{\circ} \mathrm{C}$. On the day before transfection, A2780 cells $\left(2 \times 10^{5}\right)$ with log-phase growth were seeded onto 24 -well plates containing RPMI-1640 without fetal bovine serum or antibiotics. The cells were divided into negative control (NC) and miR-138 mimic groups. When the cells reached 70-80\% confluence, $1.5 \mu \mathrm{lmiR}-138 \mathrm{mimic}$ (5'-AGCUGG UGUUGUGAAUCAGGCCG-3'; $25 \mathrm{pmol} / \mu \mathrm{l}$ ) or miR-NC (cat. no. miR01201-1-5; both Guangzhou RiboBio Co., Ltd., Guangzhou, China) and $1 \mu 1$ liposome (Lipofectamine ${ }^{\circledR}$ 2000) were mixed with $50 \mu 1$ OptiMEM medium (both Thermo Fisher Scientific, Inc.), in individual Eppendorf tubes. Following standing for $5 \mathrm{~min}$, the contents of the two Eppendorf tubes were mixed and kept at room temperature for $20 \mathrm{~min}$, followed by addition into each culture well of a 24-well plate $\left(1 \times 10^{5}\right.$ cells/well). After an incubation at $37^{\circ} \mathrm{C}$ for
$6 \mathrm{~h}$, the medium was replaced with fresh RPMI-1640 medium supplemented with $10 \%$ fetal bovine serum, and the cells were cultured under $37^{\circ} \mathrm{C}$ and $5 \% \mathrm{CO}_{2}$ for $48 \mathrm{~h}$ prior to use.

For the target gene function analysis, the cells were transfected with small interfering RNA (siR)-SOX12 (5'-CATGGC GGATTACCCGGACTA-3') and siR-NC (5'-UUTCCUCCG AACGUGUCACGUtt-3'; Hanbio Biotechnology Co., Ltd., Shanghai, China) instead of miR-138 mimic and miR-NC, using the same transfection procedure as described above.

For the rescue study, the cells were infected with lentiviral vector with overexpression of SOX12 (LV-GFP-Puro-sox12; Hanbio Biotechnology Co., Ltd.) with multiplicity of infection of 20 . Following incubation at $37^{\circ} \mathrm{C}$ for $72 \mathrm{~h}$, the cells were harvested for further use.

Reverse transcription-quantitative polymerase chain reaction (RT-qPCR). Ovarian cancer and control tissues (100 mg) were ground into powder in liquid nitrogen and mixed with $1 \mathrm{ml}$ TRIzol (Thermo Fisher Scientific, Inc.) for lysis. Then, total RNA was extracted using the phenol chloroform method (21). The purity of RNA was determined by A260/A280 using ultraviolet spectrophotometry (Nanodrop 2000 Spectrophotometer; Thermo Fisher Scientific, Inc.). Then, cDNA was obtained by $\mathrm{RT}$ at $37^{\circ} \mathrm{C}$ for $1 \mathrm{~h}$ using a Reverse Transcription system (Takara Biotechnology Co., Ltd., Dalian, China) from $1 \mu \mathrm{g}$ RNA and stored at $-20^{\circ} \mathrm{C}$.

The expression of miR-138 was determined using an SYBR PrimeScript RT-PCR kit (Takara Biotechnology Co., Ltd.), using U6 as internal reference. The reaction system (20 $\mu \mathrm{l}$ ) contained $10 \mu \mathrm{l}$ qPCR mix, $0.5 \mu \mathrm{l}$ upstream primer (miR-138, 5'-AGCTGGUGTTGTGAATCAGGCCG-3'; U6, 5'-CTCGCTTCGGCAGCACA-3'), $0.5 \mu 1$ downstream universal primer (miR-138, provided by the kit; U6, 5'-AAC GCTTCACGAATTTGCGT-3'), $1 \mu \mathrm{l}$ cDNA and $8 \mu 1 \mathrm{ddH}_{2} \mathrm{O}$. The reaction protocol was: Initial denaturation at $95^{\circ} \mathrm{C}$ for $10 \mathrm{~min}$, followed by 40 cycles of $95^{\circ} \mathrm{C}$ for $1 \mathrm{~min}$ and $60^{\circ} \mathrm{C}$ for $30 \mathrm{sec}$ (iQ5; Bio-Rad Laboratories, Inc., Hercules, CA, USA). The $2^{-\Delta \Delta \mathrm{Ct}}$ method (22) was used to calculate the relative expression of miR-138 against the internal reference. Each sample was tested in triplicate.

Cell Counting Kit 8 (CCK-8) assay. Cells were seeded at 2,000 cells/well in 96-well plates for transfection. At $48 \mathrm{~h}$ after transfection, the cells were subjected to CCK- 8 assay in order to evaluate proliferation rates. At 24,48 and $72 \mathrm{~h}$ after the initial $48 \mathrm{~h}$ of transfection, the RPMI-1640 medium was discarded, and the cells were washed with phosphate-buffered saline twice, followed by the addition of $10 \%$ CCK- 8 reaction reagent (Beyotime Institute of Biotechnology, Shanghai, China) diluted in RPMI-1640 medium at $37^{\circ} \mathrm{C}$. After incubation at $37^{\circ} \mathrm{C}$ for $1 \mathrm{~h}$, the absorbance of each well was measured at $490 \mathrm{~nm}$ for plotting cell viability curves. Each group was tested in three replicate wells and the values were averaged.

Flow cytometry. Cells $\left(1 \times 10^{6}\right)$ were washed with phosphate-buffered saline three times before centrifugation at $500 \mathrm{x} \mathrm{g}$ for $5 \mathrm{~min}$ at room temperature. After discarding the supernatant, the cells were subjected to cell cycle determination using a BD Pharmingen Cell Cycle kit (BD Biosciences, Franklin Lakes, NJ, USA) according to the manufacturer's 
protocol. Briefly, the cells were mixed with $150 \mu \mathrm{l} \mathrm{A}$ solution before gentle mixing and standing for $10 \mathrm{~min}$ at room temperature. Then, $150 \mu \mathrm{l} \mathrm{B}$ solution was added before gentle mixing and standing for $10 \mathrm{~min}$ at room temperature. After addition of $120 \mu \mathrm{l} \mathrm{C}$ solution, the cells were incubated in the dark for 15 min before flow cytometry (FACSVerse ${ }^{\mathrm{TM}}$; BD Biosciences). ModFit 3.1 software (BD Biosciences) was used to analyze the data.

Western blotting. Ovarian cancer and control tissues were ground into powder in liquid nitrogen and $100 \mathrm{mg}$ of the powder was mixed with $100 \mu \mathrm{l}$ precooled radio-immunoprecipitation assay lysis buffer (Beyotime Institute of Biotechnology) containing $1 \%$ phenylmethylsulfonyl fluoride for lysis overnight at $4^{\circ} \mathrm{C}$. Then, the mixture was centrifuged at $12,000 \mathrm{x} \mathrm{g}$ and $4^{\circ} \mathrm{C}$ for $15 \mathrm{~min}$. The supernatant was used to determine protein concentration with a bicinchoninic acid protein concentration determination kit (RTP7102; Real-Times Biotechnology Co., Ltd., Beijing, China). Protein samples $(50 \mu \mathrm{g})$ were then mixed with $5 \mathrm{X}$ sodium dodecyl sulfate (SDS) loading buffer before denaturation in a boiling water bath for $10 \mathrm{~min}$. Afterwards, the samples (20 $\mu \mathrm{g} /$ lane) were subjected to $10 \%$ SDS-PAGE at $100 \mathrm{~V}$. The resolved proteins were transferred to polyvinylidene difluoride membranes on ice $(100 \mathrm{~V}, 1 \mathrm{~h})$ and blocked with $50 \mathrm{~g} / \mathrm{L}$ skimmed milk at room temperature for $1 \mathrm{~h}$. Then, the membranes were incubated with mouse anti-human SOX12 (1:1,000; cat. no. SAB1409702; Sigma-Aldrich; Merck KGaA, Darmstadt, Germany) and GAPDH (1:5,000; cat. no. ab8245; Abcam, Cambridge, UK) polyclonal primary antibodies at $4^{\circ} \mathrm{C}$ overnight. Following five washes with phosphate-buffered saline with Tween-20 (5 min/wash), the membranes were incubated with polyclonal goat anti-mouse horseradish peroxidase-conjugated secondary antibody (1:10,000; cat. no. ab6789; Abcam) for $1 \mathrm{~h}$ at room temperature. The membranes were washed five times with phosphate-buffered saline with Tween-20 (5 min/wash), then developed using an enhanced chemiluminescence detection kit (Sigma-Aldrich; Merck KGaA) for imaging. Image Lab v3.0 software (Bio-Rad Laboratories, Inc.) was used to acquire and analyze imaging signals. The relative expression of SOX12 protein was calculated against GAPDH.

Transwell assay. For invasion assay, Matrigel was thawed at $4^{\circ} \mathrm{C}$ overnight and diluted with serum-free RPMI-1640 medium (dilution 1:1). The mixture $(20 \mu \mathrm{l})$ was evenly smeared into the upper chamber of a Transwell insert (Merck $\mathrm{KGaA}$ ) and incubated at $37^{\circ} \mathrm{C}$ for $1 \mathrm{~h}$. For migration assay, Matrigel was not added. After solidification, $1 \times 10^{5}$ cells from each group were seeded into the upper chamber containing $200 \mu 1$ serum-free RPMI-1640 medium. In addition, $500 \mu \mathrm{l}$ RPMI-1640 medium supplemented with $10 \%$ fetal bovine serum was added into the lower chamber. After $48 \mathrm{~h}$, the chamber was removed and the cells in the upper chamber were wiped off. After being fixed with $4 \%$ formaldehyde for $10 \mathrm{~min}$, the membrane was stained at room temperature for $2 \mathrm{~h}$ using the Giemsa method for light microscopic observation of 5 random fields (magnification, x200). The number of cells was calculated for the evaluation of cell invasion and migration ability. All procedures were performed on ice with pipetting tips being cooled at $4^{\circ} \mathrm{C}$.
Dual luciferase reporter assay. Bioinformatics prediction is a powerful tool for the study of the functions of miRNAs. To understand the regulatory mechanism of SOX12 in ovarian cancer, miRanda (www.microrna.org/microrna/home. do), TargetScan (www.targetscan.org), PiTa (http://genie. weizmann.ac.il/pubs/mir07/mir07_data.html), RNAhybrid (http://bibiserv.techfak.uni-bielefeld.de/rnahybrid/) and PICTA (http://pictar.mdc-berlin.de/) databases were used to predict miRNA molecules that may regulate SOX12. It was identified that miR-138 was potentially able to regulate SOX12. According to bioinformatics results, wild-type (WT) and mutant seed regions of miR-138 in the 3'-UTR of SOX12 gene were chemically synthesized in vitro, with SpeI and HindIII restriction sites added. These were then cloned into pMIR-REPORT luciferase reporter plasmids (Thermo Fisher Scientific, Inc.). Using Lipofectamine 3000 (Thermo Fisher Scientific, Inc.), plasmids $(0.8 \mu \mathrm{g})$ with WT or mutant 3'-UTR DNA sequences were co-transfected with agomiR-138 (100 nM; Sangon Biotech, Shanghai, China) into 293T cells (American Type Culture Collection, Manassas, VA, USA). Following cultivation for $24 \mathrm{~h}$, the cells were lysed using Dual-Luciferase ${ }^{\circledR}$ Reporter Assay System (Promega Corporation, Madison, WI, USA) according to the manufacturer's protocol, and fluorescence intensity was measured using a GloMax 20/20 luminometer (Promega Corporation). Using Renilla fluorescence activity as an internal reference, the fluorescence values of each group of cells were measured.

Statistical analysis. Statistical analysis was performed using SPSS 11.0 (SPSS, Inc., Chicago, IL, USA). Measurement data were expressed as the mean \pm standard deviation. Data were tested for normality. Two groups of data were compared using t-tests. Multiple groups of data were analyzed using one-way analysis of variance. In cases of homogeneity of variance, the Student-Newman-Keuls post hoc test was used for multiple comparisons. $\mathrm{P}<0.05$ was considered to indicate a statistically significant difference.

\section{Results}

Expression of miR-138 is associated with the early occurrence and metastasis of ovarian cancer. To measure the expression of miR-138 in ovarian cancer tissues, RT-qPCR was performed. The data indicated that the level of miR-138 in ovarian cancer tissues was significantly lower compared with the control tissues $(\mathrm{P}<0.05$; Fig. 1A). In addition, the level of miR-138 in ovarian cancer patients with lymphatic metastasis was significantly lower compared with in patients without lymphatic metastasis $(\mathrm{P}<0.05$; Fig. 1B). Compared with the control group, the level of miR-138 in ovarian cancer tissues at stages I, II, III and IV was significantly reduced $(\mathrm{P}<0.05)$, but no significant differences were observed among the four stages (Fig. 1C). These results suggest that the expression of miR-138 is associated with the early occurrence and metastasis of ovarian cancer.

Upregulation of $\mathrm{miR}-138$ inhibits the proliferation of $A 2780$ cells. To evaluate the effect of miR-138 on the proliferation of A2780 cells, a CCK-8 assay was performed. The data indicated that the absorbance of cells transfected with miR-138 


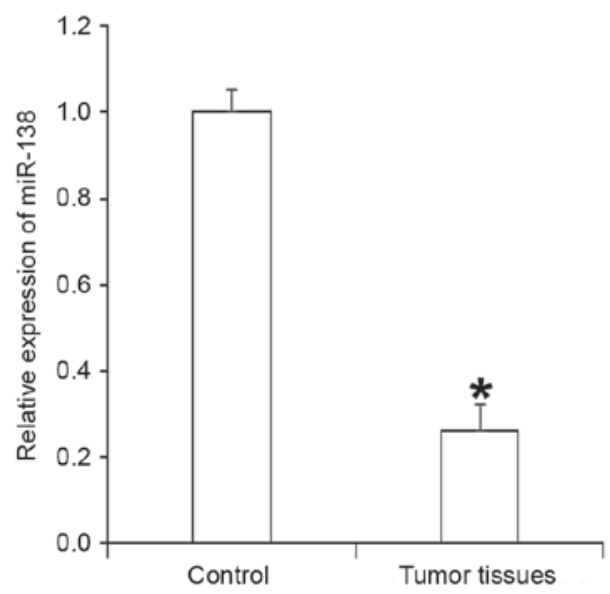

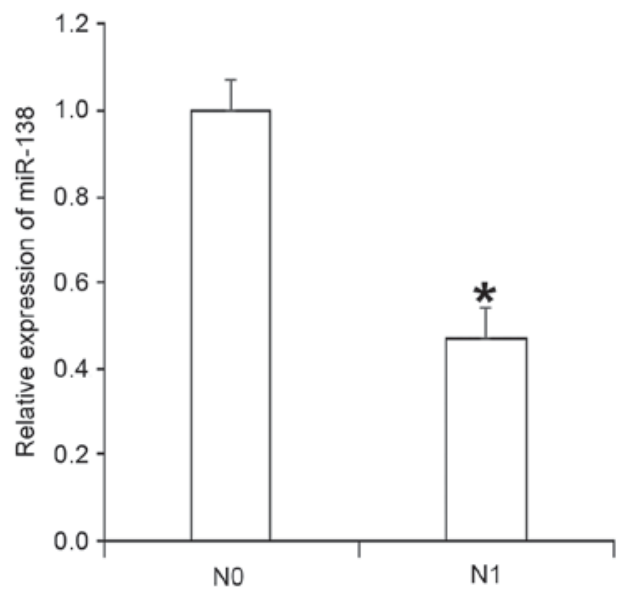

C

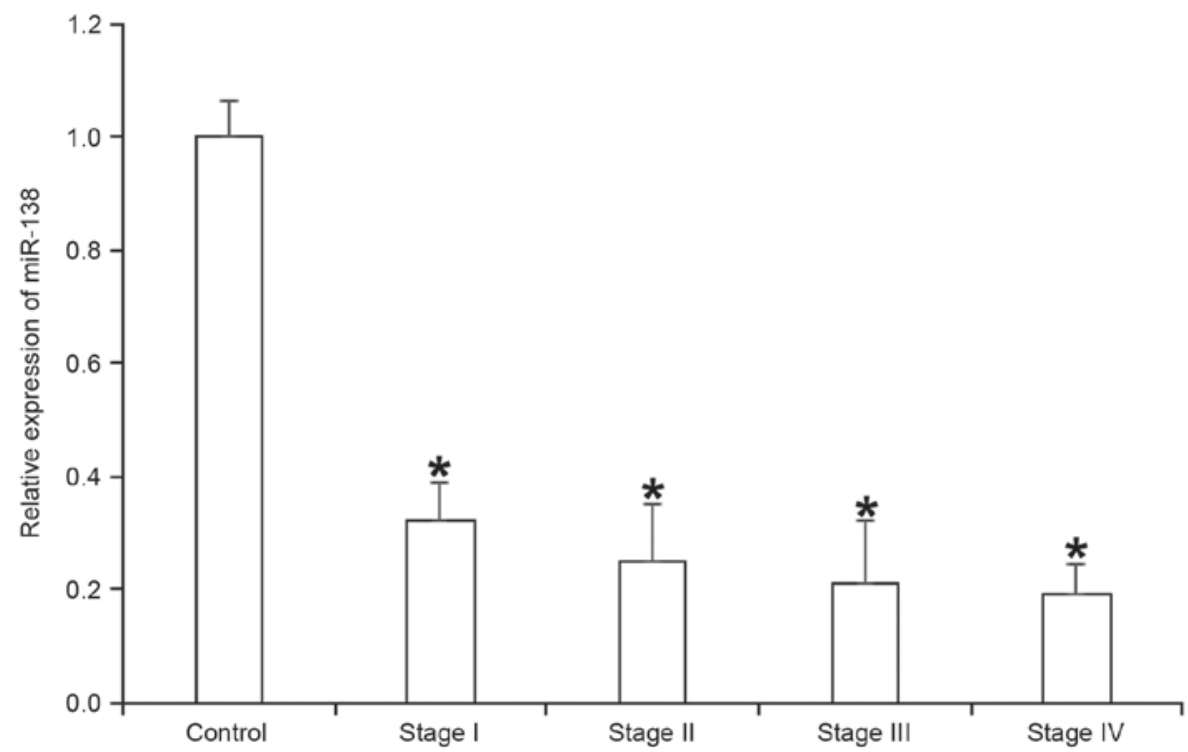

Figure 1. Expression of miR-138 in ovarian cancer. (A) miR-138 expression in ovarian cancer tissues and control tissues. "P<0.05 vs. control. (B) miR-138 expression in patients with ovarian cancer with $(25$ cases) or without ( 22 cases) lymphatic metastasis. " $\mathrm{P}<0.05$ vs. N0. (C) miR-138 expression in patients with ovarian cancer at stages I, II, III and IV. "P<0.05 vs. control. Differences among stages I, II, III and IV were compared by ANOVA and post-hoc test, but no statistically significant differences were identified. Relative expression of miR-138 was measured using reverse transcription quantitative polymerase chain reaction. miR, microRNA; N0, no lymphatic metastasis; N1, lymphatic metastasis.

mimic was significantly lower compared with cells transfected with miR-NC at 48 and $72 \mathrm{~h}(\mathrm{P}<0.05$; Fig. 2). These results indicate that upregulation of miR-138 inhibits the proliferation of A2780 cells.

Overexpression of miR-138 inhibits the proliferation of $A 2780$ cells by suppressing their $G_{I} / S$ phase transition. To detect cell cycle distribution, flow cytometry was performed. The data indicated that the percentage of $\mathrm{G}_{1}$ phase cells in the miR-138 mimic group was significantly higher compared with the miR-NC group $(\mathrm{P}<0.05)$, while the percentage of $\mathrm{S}$ phase cells in the miR-138 mimic group was significantly lower compared with the miR-NC group ( $\mathrm{P}<0.05$; Fig. 3). These results suggest that overexpression of $\mathrm{miR}-138$ inhibits the proliferation of A2780 cells by suppressing their $\mathrm{G}_{1} / \mathrm{S}$ phase transition.

miR-138 suppresses the invasion and migration of A2780 cells. To investigate the invasion and migration abilities of

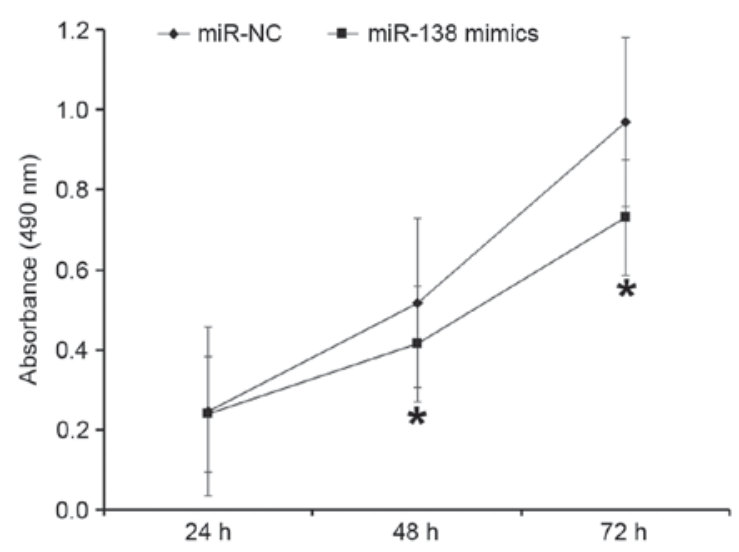

Figure 2. Proliferation of A2780 cells at 24, 48 and $72 \mathrm{~h}$ after transfection with miR-NC or miR-138 mimic. A Cell Counting Kit 8 assay was used to determine the proliferation of the cells. Absorbance of each well was measured at $490 \mathrm{~nm}$ with a microplate reader and cell viability curves were plotted. " $\mathrm{P}<0.05$ vs. miR-NC group. NC, negative control; miR, microRNA. 
A

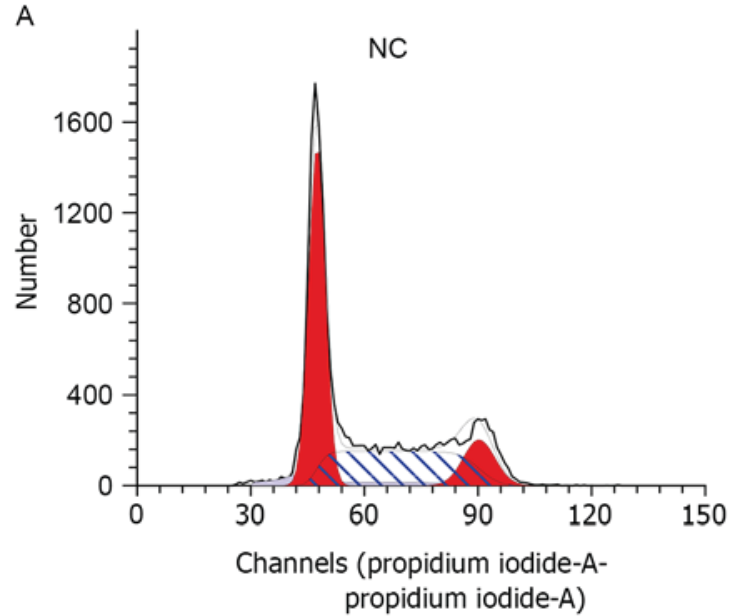

B

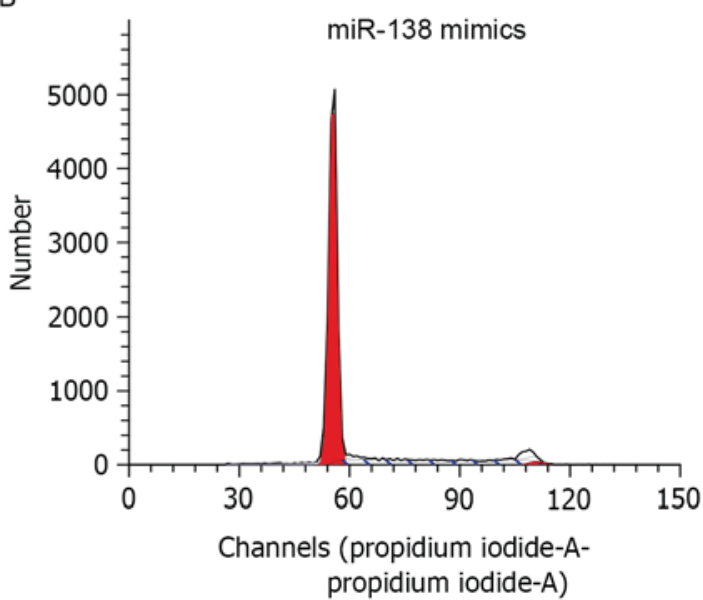

C

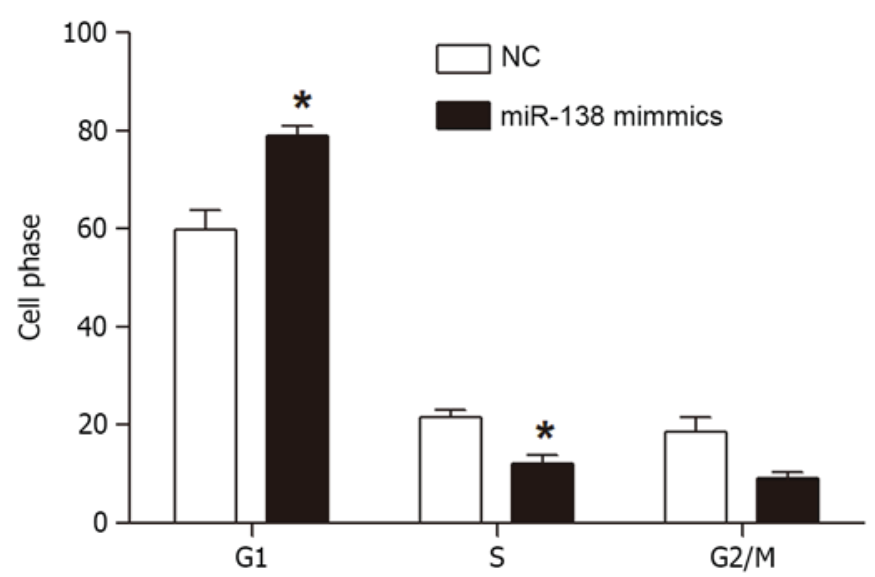

Figure 3. Effect of miR-138 on A2780 cell cycle as determined by flow cytometry. Representative flow cytometry graphs of (A) miR-NC and (B) miR-138 mimic groups. (C) Percentages of cells in $\mathrm{G}_{1}, \mathrm{~S}$ and $\mathrm{G}_{2} / \mathrm{M}$ phases. " $\mathrm{P}<0.05$ vs. miR-NC group. NC, negative control; miR, microRNA.

A
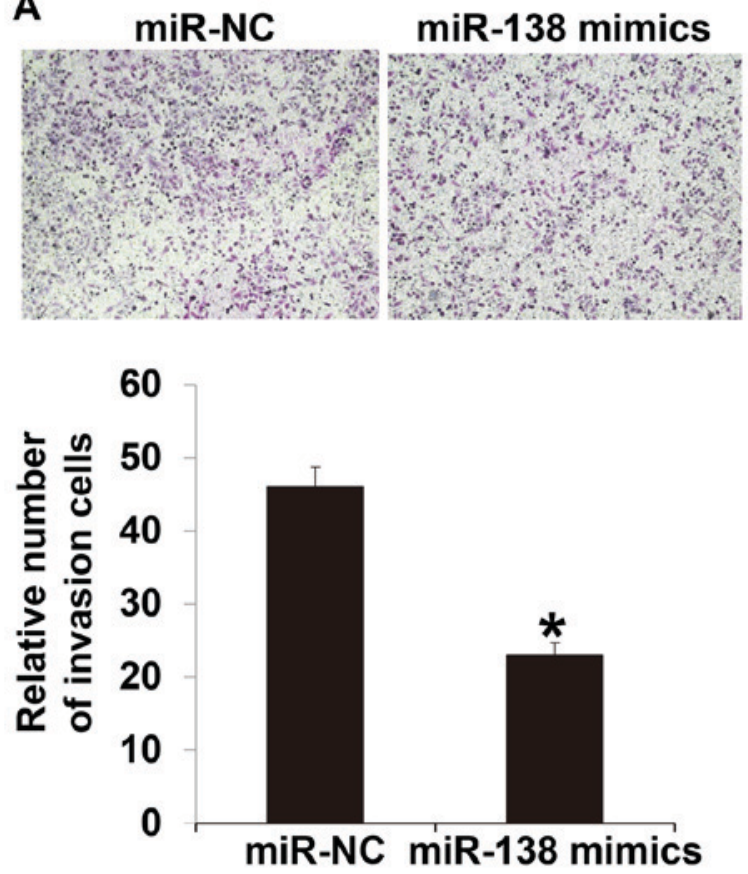

B
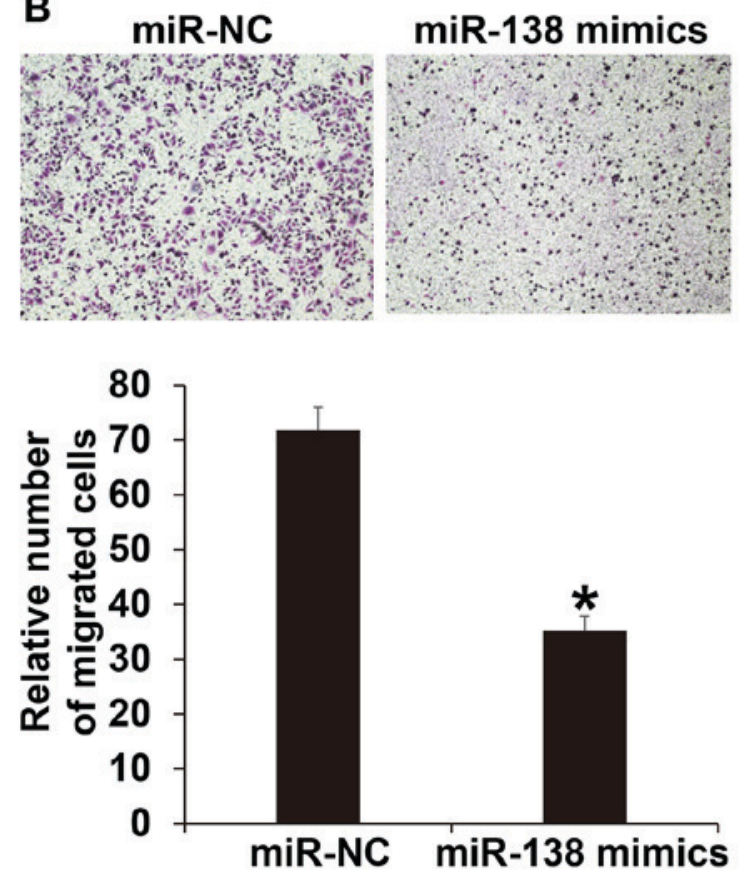

Figure 4. Effect of miR-138 on the (A) invasion and (B) migration abilities of A2780 cells transfected with miR-NC or miR-138 mimics. A Transwell assay with or without Matrigel was used to determine the invasion and migration abilities of the cells, respectively. Magnification, $\mathrm{x} 100$. * $\mathrm{P}<0.05 \mathrm{vs}$. miR-NC group. NC, negative control; miR, microRNA. 


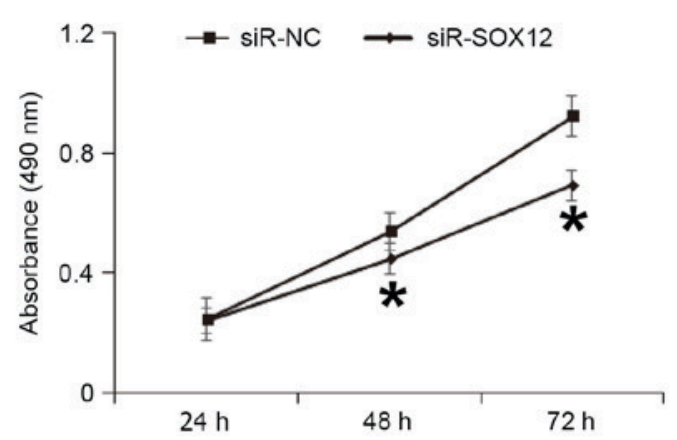

C
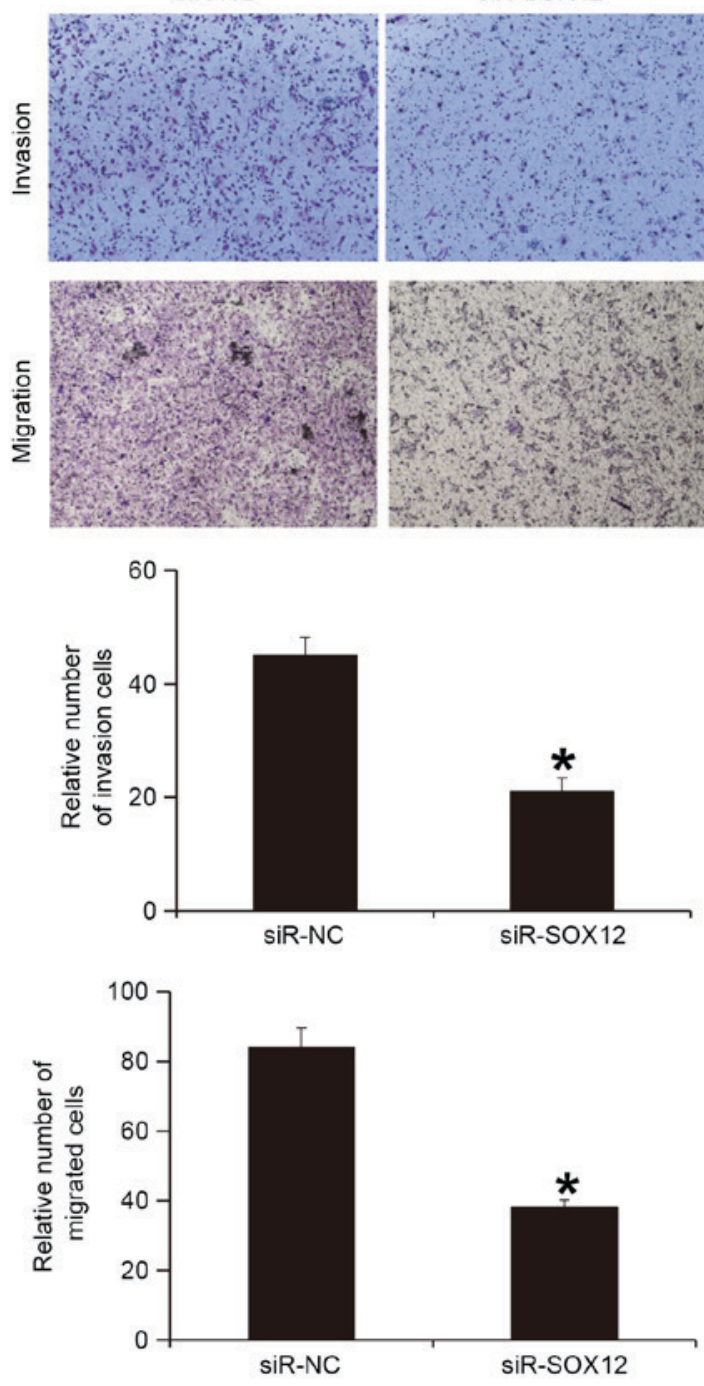

B

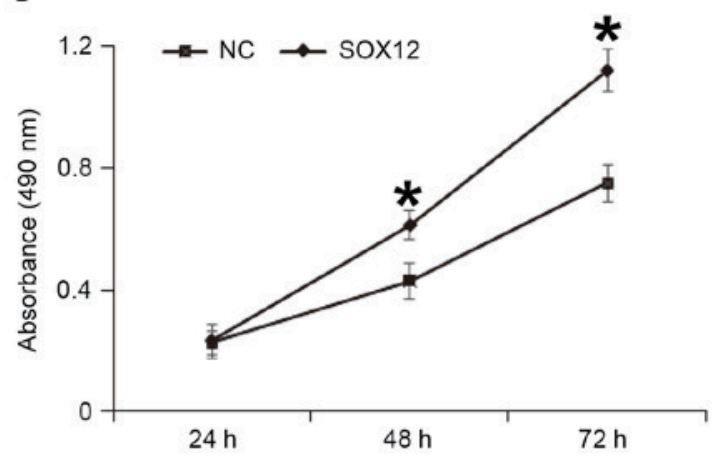

D
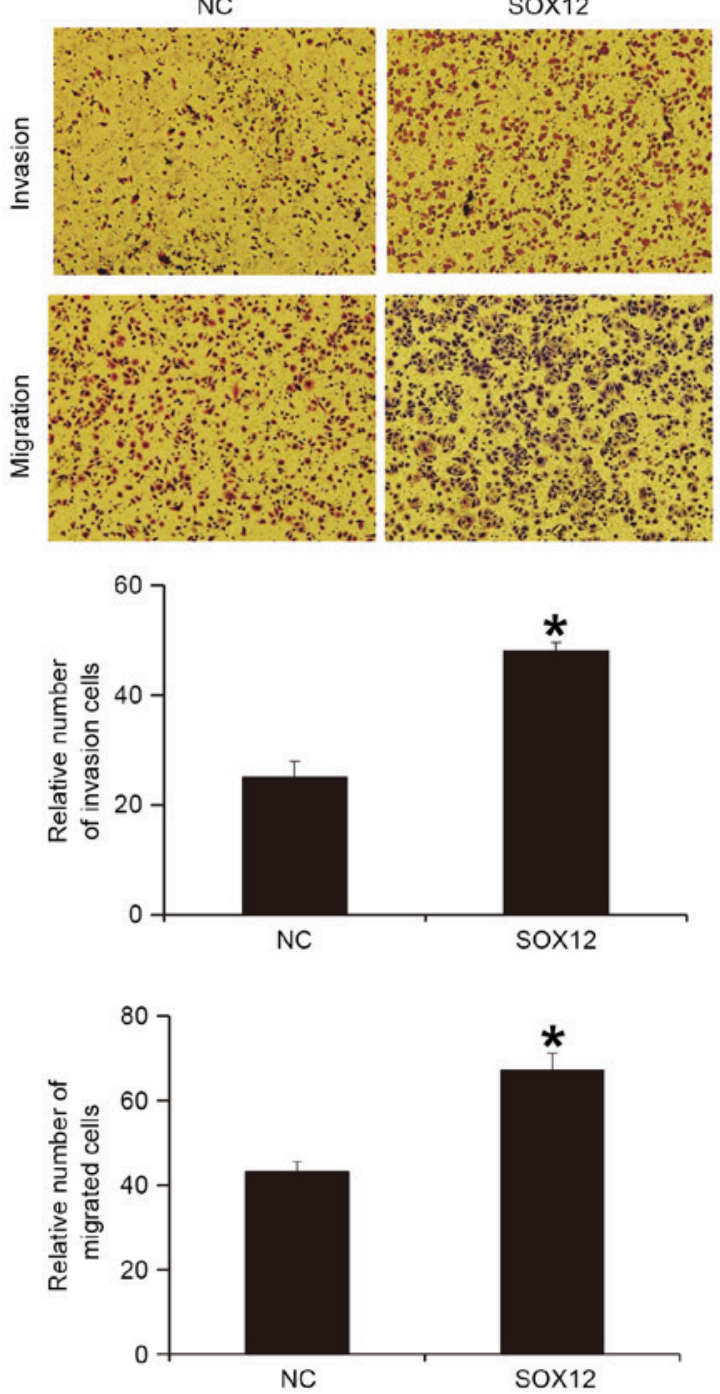

Figure 5. Effect of SOX12 expression on the proliferation, invasion and migration abilities of A2780 cells. (A) Proliferation of A2780 cells at 24,48 and $72 \mathrm{~h}$ after transfection with siR-NC or siR-SOX12. ${ }^{*} \mathrm{P}<0.05$ vs. siR-NC group. (B) Proliferation of A2780 cells at 24,48 and $72 \mathrm{~h}$ after transfection with NC or SOX12. "P<0.05 vs. NC group. (C) Images and relative numbers of invaded and migrated cells following transfection with siR-NC or siR-SOX12. ${ }^{*} \mathrm{P}<0.05$ vs. siR-NC group. (D) Images and relative numbers of invaded and migrated cells following transfection with NC or SOX12. Magnification, x100. ${ }^{*} \mathrm{P}<0.05 \mathrm{vs}$. NC group. NC, negative control; siR, small interfering RNA.

A2780 cells, Transwell assays were used. The invasion assay indicated that the number of cells that crossed the Transwell membrane in the miR-138 mimic group was significantly lower compared with the miR-NC group $(\mathrm{P}<0.05$; Fig. $4 \mathrm{~A})$. Similarly, the migration assay indicated that the number of cells that crossed the Transwell membrane in the miR-138 mimics group was significantly reduced compared with the miR-NC group $(\mathrm{P}<0.05$; Fig. $4 \mathrm{~B})$. These results suggest that miR-138 suppresses the invasion and migration of A2780 cells. 
A
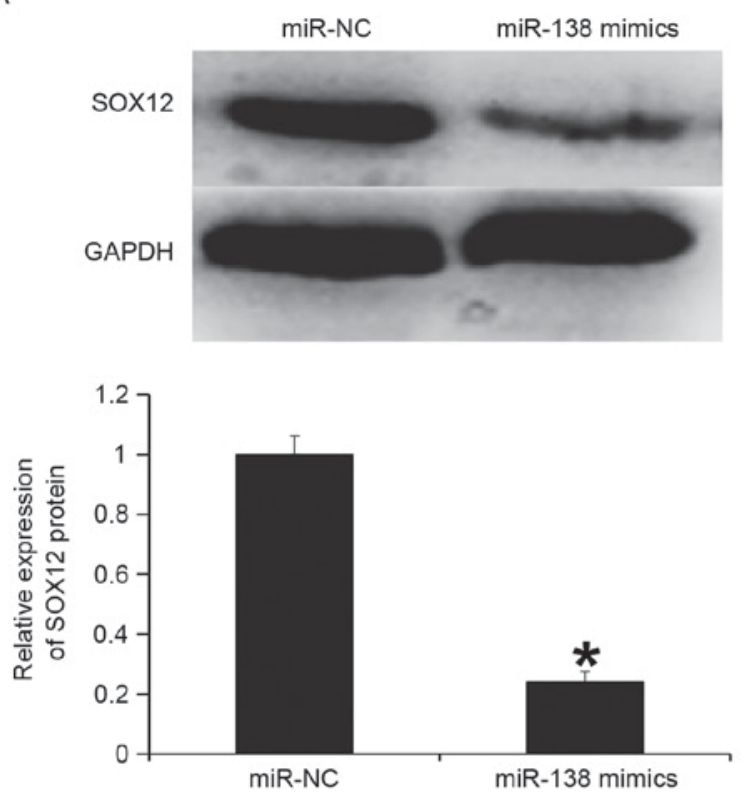

C
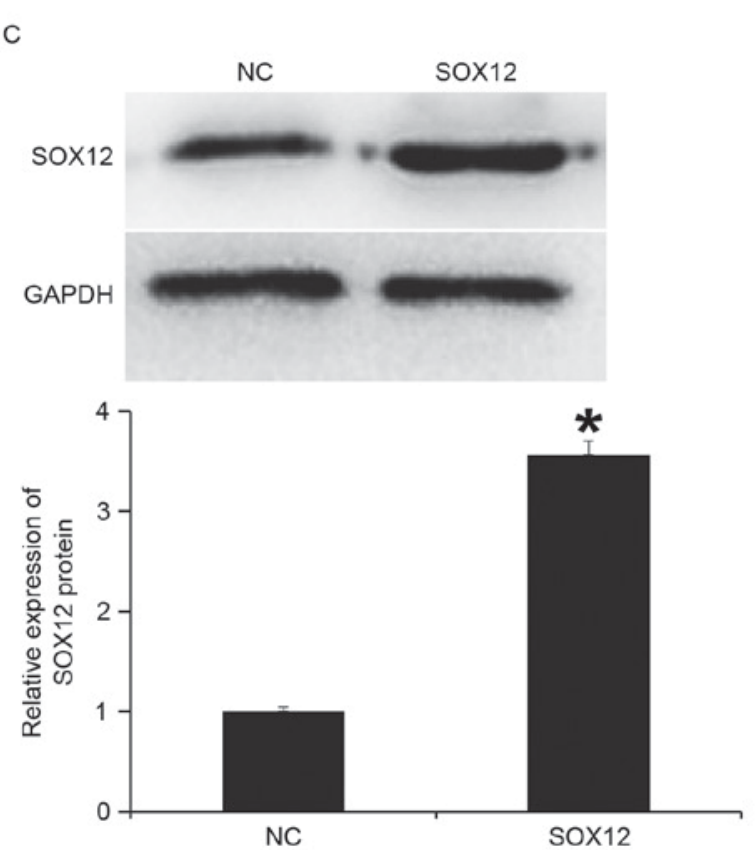

B
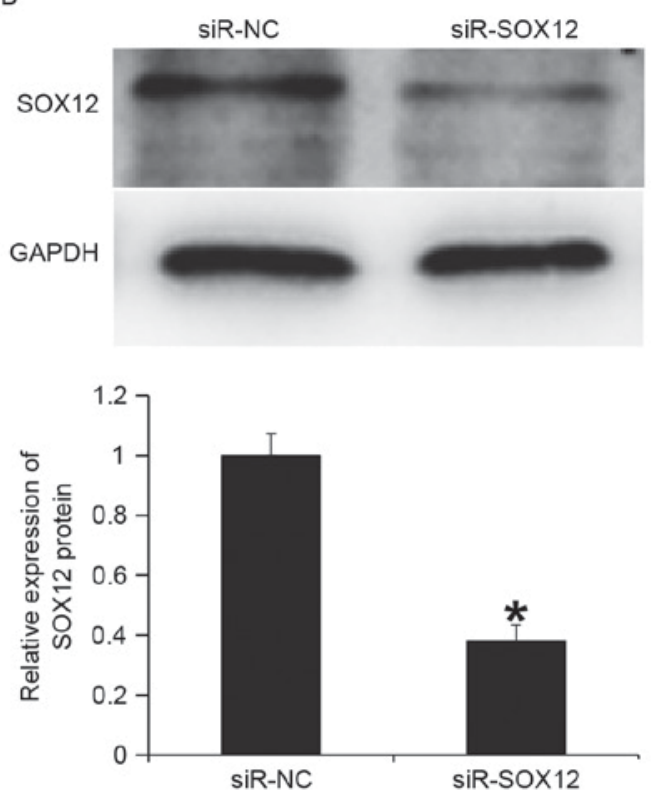

Figure 6. Protein expression of SOX12 in A2780 cells following transfection with (A) miR-138 mimics, (B) siR-SOX12 or (C) LV-GFP-Puro-sox12. Western blotting was used to measure SOX12 protein expression. " $\mathrm{P}<0.05$ vs. relative control group. NC, negative control; siR, small interfering RNA; miR, microRNA.

SOX12 promotes the proliferation, invasion and migration of A2780 cells. To examine whether the expression of SOX12 protein regulates the biological functions of A2780 cells, SOX12 gene was silenced or overexpressed in A2780 cells. A CCK-8 assay indicated that silencing of SOX12 expression significantly reduced the proliferation of A2780 cells at 47 and $72 \mathrm{~h}(\mathrm{P}<0.05$; Fig. 5A), while overexpression of SOX12 significantly enhanced the proliferation of A2780 cells at 48 and $72 \mathrm{~h}(\mathrm{P}<0.05$; Fig. 5B). A Transwell assay indicated that silencing of SOX12 expression significantly decreased the invasion and migration abilities of A2780 cells $(\mathrm{P}<0.05$; Fig. 5C), while overexpression of SOX12 significantly increased the invasion and migration abilities of A2780 cells $(\mathrm{P}<0.05$; Fig. 5D). These results indicate that SOX12 promotes the proliferation, invasion and migration of A2780 cells.

miR-138 downregulates the protein expression of SOX12. To determine protein expression, western blotting was performed. The data indicated that the expression of SOX12 protein in the miR-138 mimics group was significantly lower compared with the miR-NC group ( $\mathrm{P}<0.05$; Fig. 6A). Transfection with siR-SOX12 significantly reduced SOX12 protein expression compared with the siR-NC group ( $\mathrm{P}<0.05$; Fig. 6B). In addition, SOX12 protein expression in cells with overexpression of SOX12 was significantly higher compared with the NC $(\mathrm{P}<0.05$; Fig. 6C). These results indicate that miR-138 downregulates the protein expression of SOX12. 


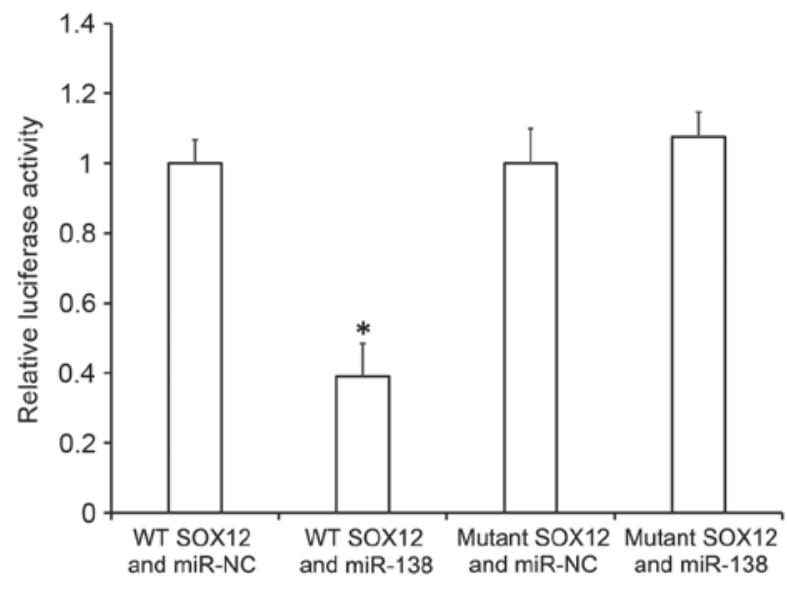

Figure 7. Fluorescence values of $293 \mathrm{~T}$ cells transfected with WT or mutant 3'-UTR DNA sequences of SOX12 and miR-138 mimics. Dual luciferase reporter assay was performed to evaluate the interaction between miR-138 and SOX12. ${ }^{*} \mathrm{P}<0.05$ vs. miR-NC for WT. NC, negative control; miR, microRNA; WT, wild-type.

miR-138 downregulates the expression of SOX12 by binding with the 3'-UTR of SOX12 gene. To understand whether miR-138 directly targets SOX12, a dual luciferase reporter assay was performed. The data indicated that transfection with miR-138 mimics and pMIR-REPORT-wild type SOX12 led to significantly reduced fluorescence intensity compared with the miR-NC group $(\mathrm{P}<0.05)$, while transfection with miR-138 mimics and pMIR-REPORT-mutant SOX12 resulted in similar fluorescence intensity compared with the miR-NC group (Fig. 7). These results suggest that miR-138 downregulates the expression of SOX12 by binding with the 3'-UTR of SOX12 gene.

\section{Discussion}

Previous studies have reported that miRNA molecules have important functions in the occurrence and development of tumors by widely participating in processes including proliferation, differentiation, apoptosis and cell cycle $(23,24)$. For example, miR-590 inhibits the occurrence and metastasis of NSCLC via targeted regulation of ADAM9 gene expression (25). In addition, miR-146a acts as a tumor-suppressor gene by inhibiting the proliferation, invasion and metastasis of cervical cancer and colon cancer cells (26). However, certain miRNA molecules may promote the occurrence and development of tumors. For example, miR-574-5 promotes the distant metastasis of NSCLC by targeting PTPRU gene, while miR-10b facilitates the proliferation and metastasis of hepatocellular carcinoma by downregulating the expression of CUB and Sushi multiple domains 1 (27). In the present study, it was identified that miR-138 expression is significantly reduced in ovarian cancer cells, and the level of miR-138 in patients with lymphatic metastasis is significantly lower compared with patients without lymphatic metastasis, suggesting that miR-138 expression is associated with the invasion and migration of ovarian cancer cells. In addition, the levels of miR-138 in ovarian cancer patients at stages I, II, III and IV are not significantly different from each other, suggesting that miR-138 is associated with the early occurrence of ovarian cancer. At the cellular level, it was identified that overexpression of miR-138 inhibits the proliferation, invasion and migration of A2780 cells. This suggests that miR-138 acts as a tumor-suppressor gene in the occurrence and development of ovarian cancer and the downregulation of miR-138 promotes the proliferation, invasion and migration of ovarian cancer cells.

SOX genes, members of the high mobility group superfamily, primarily encode transcription factors $(28,29)$. SOX genes have been demonstrated to be associated with the differentiation and proliferation of cells (30), and have oncogene functions $(31,32)$. It is reported that SOX10 and SOX1 are tumor-associated antigens of melanoma and small cell lung cancer cells, respectively $(33,34)$. The expression of SOX genes is not the same in different tumor types. For example, SOX7 expression is upregulated in esophageal squamous cell carcinoma and gastric carcinoma (35), but is downregulated in prostate cancer, breast cancer and rectal cancer (36). SOX12 is a member of the SOX family, but its function and mechanism of action in tumors is not yet clear. A previous study demonstrated that SOX12 is upregulated in breast cancer and promotes the invasion and migration of tumor cells (37). Huang et al (38) demonstrated that SOX12 directly regulates FoxQ1, upregulates the expression of Twist1 and FGFBP1, and facilitates the invasion and metastasis of hepatocellular carcinoma. In the present study, it was identified that miR-138 regulates the SOX12 gene by directly binding with the 3'-UTR of SOX12 and inhibiting the expression of SOX12 protein. In addition, overexpression of SOX12 gene in A2780 cells promoted the proliferation, invasion and migration of A2780 cells, while silencing of SOX12 gene reduced the proliferation, invasion and migration of the cells, suggesting that SOX12 gene is an oncogene in A2780 cells. Furthermore, miR-138 inhibits the occurrence and development of ovarian cancer by downregulating the expression of SOX12 gene.

In the present study, changes in miRNA molecules were determined in tumor tissues. Due to the complexity of tumor tissue components, the distribution of miRNA molecules in tissues is not yet clearly known. One of the limitations of the present study is the absence of in situ hybridization to determine the expression of miRNA in specimens observed by microscopy.

In conclusion, miR-138 expression is downregulated in ovarian cancer and thus, SOX12 gene expression is upregulated and the occurrence and development of ovarian cancer is promoted. Therefore, miR-138 is a potential therapeutic target and biomarker for ovarian cancer.

\section{Acknowledgements}

The present study was supported by the Affiliated Hospital of Jining Medical University. The authors would also like to thank Dr Dongmei Man, Director of the Affiliated Hospital of Jining Medical University.

\section{Funding}

No funding was received. 


\section{Availability of data and materials}

The datasets used and/or analyzed during the current study are available from the corresponding author on reasonable request.

\section{Authors' contributions}

The final version of the manuscript has been read and approved by all authors, and each author believes that the manuscript represents honest work. MQ and YZ collaborated to design the study. MQ and MJ were responsible for experiments. MQ, MJ and $\mathrm{YZ}$ analyzed the data. All authors collaborated to interpret results and develop the manuscript.

\section{Ethics approval and consent to participate}

All procedures performed in the current study were approved by the Ethics Committee of Jining Medical University. Written informed consent was obtained from all patients or their families.

\section{Patient consent for publication}

Written informed consents for publication of any associated data and accompanying images were obtained from all patients or their parents, guardians or next of kin.

\section{Competing interests}

The authors declare that they have no competing interests.

\section{References}

1. Lam SS, Ip CK, Mak AS and Wong AS: A novel p70 S6 kinase-microRNA biogenesis axis mediates multicellular spheroid formation in ovarian cancer progression. Oncotarget 7 38064-38077, 2016

2. Querleu D, Meurette J, Darai E, Morice P and Planchamp F: Surgical management of ovarian cancer: Trends in clinical practice. Bull Cancer 103: 935-940, 2016 (In French).

3. Wen B, Campbell KR, Tilbury K, Nadiarnykh O, Brewer MA, Patankar M, Singh V, Eliceiri KW and Campagnola PJ: 3D texture analysis for classification of second harmonic generation images of human ovarian cancer. Sci Rep 6: 35734, 2016.

4. Yang Z, Xu S, Jin P, Yang X, Li X, Wan D, Zhang T, Long S, Wei X, Chen G, et al: MARCKS contributes to stromal cancer-associated fibroblast activation and facilitates ovarian cancer metastasis. Oncotarget 7: 37649-37663, 2016.

5. Correa DD, Root JC, Kryza-Lacombe M, Mehta M, Karimi S, Hensley ML and Relkin N: Brain structure and function in patients with ovarian cancer treated with first-line chemotherapy: Apilot study. Brain Imaging Behav 11: 1652-1663, 2017.

6. Tomar T, de Jong S, Alkema NG, Hoekman RL, Meersma GJ, Klip HG, van der Zee AG and Wisman GB: Genome-wide methylation profiling of ovarian cancer patient-derived xenografts treated with the demethylating agent decitabine identifies novel epigenetically regulated genes and pathways. Genome Med 8: $107,2016$.

7. Harada T, Nakamura Y, Sato K, Nagaya T, Okuyama S, Ogata F, Choyke PL and Kobayashi H: Near-infrared photoimmunotherapy with galactosyl serum albumin in a model of diffuse peritoneal disseminated ovarian cancer. Oncotarget 7: 79408-79416, 2016.

8. Halpern JA, Shoag JE, Mittal S, Oromendia C, Ballman KV, Hershman DL, Wright JD, Shih YT, Nguyen PL and Hu JC: Prognostic significance of digital rectal examination and prostate specific antigen in the prostate, lung, colorectal, and ovarian cancer screening arm. J Urol 197: 363-368, 2016.
9. Ren F, Shen J, Shi H, Hornicek FJ, Kan Q and Duan Z: Novel mechanisms and approaches to overcome multidrug resistance in the treatment of ovarian cancer. Biochim Biophys Acta 1866: 266-275, 2016.

10. Salerno L, Marchetti C, Bevilacqua E, Musella A, Riganelli L, Ruscito I, Perniola G, Muzii L and Benedetti Panici P: Beyond the beyond: First case of 9 cytoreductive surgeries in a long-surviving ovarian cancer patient: Case report. Tumori 102 (Suppl 2): 5301, 2016.

11. Matikas A, Syrigos KN and Agelaki S: Circulating biomarkers in non-small-cell lung cancer: Current status and future challenges. Clin Lung Cancer 17: 507-516, 2016.

12. Li X, Wainscott $\mathrm{C}$ and Xi Y: MicroRNA provides insight into understanding esophageal cancer. Thorac Cancer 2: 134-142, 2011.

13. Giza DE, Fuentes-Mattei E, Bullock MD, Tudor S, Goblirsch MJ, Fabbri M, Lupu F, Yeung SJ, Vasilescu C and Calin GA: Cellular and viral microRNAs in sepsis: Mechanisms of action and clinical applications. Cell Death Differ 23: 1906-1918, 2016.

14. Shah MY, Ferrajoli A, Sood AK, Lopez-Berestein G and Calin GA: microRNA therapeutics in cancer - an emerging concept. EbioMedicine 12: 34-42, 2016.

15. Shen B, Yu S, Zhang Y, Yuan Y, Li X, Zhong J and Feng J: miR-590-5p regulates gastric cancer cell growth and chemosensitivity through RECK and the AKT/ERK pathway. Onco Targets Ther 9: 6009-6019, 2016.

16. Tan Y, Hu H, Tan W, Jin L, Liu J and Zhou H: MicroRNA-138 inhibits migration and invasion of non-small cell lung cancer cells by targeting LIMK1. Mol Med Rep 14: 4422-4428, 2016.

17. Liu Y, Zhang W, Liu K, Liu S, Ji B and Wang Y: miR-138 suppresses cell proliferation and invasion by inhibiting SOX9 in hepatocellular carcinoma. Am J Transl Res 8: 2159-2168, 2016.

18. Zhao L, Yu H, Yi S, Peng X, Su P, Xiao Z, Liu R, Tang A, Li X, Liu $F$ and Shen S: The tumor suppressor miR-138-5p targets PD-L1 in colorectal cancer. Oncotarget 7: 45370-45384, 2016.

19. Yeh YM, Chuang CM, Chao KC and Wang LH: MicroRNA-138 suppresses ovarian cancer cell invasion and metastasis by targeting SOX4 and HIF-1 $\alpha$. Int J Cancer 133: 867-878, 2013.

20. Meng Q, Duan P, Li L and Miao Y: Expression of placenta growth factor is associated with unfavorable prognosis of advanced-stage serous ovarian cancer. Tohoku J Exp Med 244: 291-296, 2018.

21. Brown RAM, Epis MR, Horsham JL, Kabir TD, Richardson KL and Leedman PJ: Total RNA extraction from tissues for microRNA and target gene expression analysis: Not all kits are created equal. BMC Biotechnol 18: 16, 2018.

22. Livak KJ and Schmittgen TD: Analysis of relative gene expression data using real-time quantitative PCR and the 2(-Delta Delta C(T)) method. Methods 25: 402-408, 2001.

23. Wang J, Paris PL, Chen J, Ngo V, Yao H, Frazier ML, Killary AM, Liu CG, Liang H, Mathy C, et al: Next generation sequencing of pancreatic cyst fluid microRNAs from low grade-benign and high grade-invasive lesions. Cancer Lett 356: 404-409, 2015.

24. Chao A, Lai CH, Chen HC, Lin CY, Tsai CL, Tang YH, Huang HJ, Lin CT, Chen MY, Huang KG, et al: Serum microRNAs in clear cell carcinoma of the ovary. Taiwan J Obstet Gynecol 53: 536-541, 2014.

25. Wang FF, Wang S, Xue WH and Cheng JL: microRNA-590 suppresses the tumorigenesis and invasiveness of non-small cell lung cancer cells by targeting ADAM9. Mol Cell Biochem 423: 29-37, 2016

26. Sathyanarayanan A, Chandrasekaran KS and Karunagaran D: microRNA-146a inhibits proliferation, migration and invasion of human cervical and colorectal cancer cells. Biochem Biophys Res Commun 480: 528-533, 2016.

27. Zhu Q, Gong L, Wang J, Tu Q, Yao L, Zhang JR, Han XJ, Zhu SJ, Wang SM, Li YH and Zhang W: miR-10b exerts oncogenic activity in human hepatocellular carcinoma cells by targeting expression of CUB and sushi multiple domains 1 (CSMD1). BMC Cancer 16: 806, 2016.

28. Nagase S, Iyoda T, Kanno H, Akase T, Arakawa I, Inoue T and Uetsuka Y: Comparison of the cost-effectiveness of the sox and cox regimens in patients with unresectable advanced and recurrent colorectal cancer using a clinical decision analysis approach. Gan To Kagaku Ryoho 43: 1201-1205, 2016 (In Japanese).

29. Righi S, Pileri S, Agostinelli C, Bacci F, Spagnolo S and Sabattini E: Reproducibility of SOX-11 detection in decalcified bone marrow tissue in mantle cell lymphoma patients. Hum Pathol 59: 94-101, 2017.

30. Fu L and Shi YB: The Sox transcriptional factors: Functions during intestinal development in vertebrates. Semin Cell Dev Biol 63: 58-67, 2017 
31. Weina K, Wu H, Knappe N, Orouji E, Novak D, Bernhardt M, Hüser L, Larribère L, Umansky V, Gebhardt C and Utikal J: TGF- $\beta$ induces SOX2 expression in a time-dependent manner in human melanoma cells. Pigment Cell Melanoma Res 29: 453-458, 2016.

32. Song WS, Yang YP, Huang CS, Lu KH, Liu WH, Wu WW, Lee YY, Lo WL, Lee SD, Chen YW, et al: Sox2, a stemness gene, regulates tumor-initiating and drug-resistant properties in CD133-positive glioblastoma stem cells. J Chin Med Assoc 79: 538-545, 2016.

33. Li N and Li S: Epigenetic inactivation of SOX1 promotes cell migration in lung cancer. Tumour Biol 36: 4603-4610, 2015.

34. Gambichler T, Petig AL, Stockfleth E and Stucker M: Expression of SOX10, ABCB5 and CD271 in melanocytic lesions and correlation with survival data of patients with melanoma. Clin Exp Dermatol 41: 709-716, 2016.

35. Yang M, Cui G, Ding M, Yang W, Liu Y, Dai D and Chen L: miR-935 promotes gastric cancer cell proliferation by targeting SOX7. Biomed Pharmacother 79: 153-158, 2016.
36. Liu H, Mastriani E, Yan ZQ, Yin SY, Zeng Z, Wang H, Li QH, Liu HY, Wang X, Bao HX, et al: SOX7 co-regulates Wnt $/ \beta$-catenin signaling with Axin-2: Both expressed at low levels in breast cancer. Sci Rep 6: 26136, 2016.

37. Ding H, Quan H, Yan W and Han J: Silencing of SOX12 by shRNA suppresses migration, invasion and proliferation of breast cancer cells. Biosci Rep 36: e00389, 2016.

38. Huang W, Chen Z, Shang X, Tian D, Wang D, Wu K, Fan D and Xia L: Sox12, a direct target of FoxQ1, promotes hepatocellular carcinoma metastasis through up-regulating Twist1 and FGFBP1. Hepatology 61: 1920-1933, 2015.

(i) $\ominus$ This work is licensed under a Creative Commons Attribution-NonCommercial-NoDerivatives 4.0 International (CC BY-NC-ND 4.0) License. 